\title{
Education and competitive economy: how do cultural dimensions fit in?
}

\author{
Hoi Yan Cheung · Alex Wing Ho Chan
}

Published online: 21 July 2009

(C) Springer Science+Business Media B.V. 2009

\begin{abstract}
Globalization has changed the way people behave in different aspects of life. One of the significant differences is that people are now competing with everyone around the world, not just people within or near their own regions. A good way of remaining competitive is to provide quality education that can help students meet the needs of the competitive economy. However, not all nations are responding in the same way. Using a quantitative approach, this explorative study seeks to discover if, and how, cultural dimensions fit into the process of meeting the demands of the competitive economy by means of education across regions. Forty-three regions with different ratings on the Power Distance Index (PDI), Individualism (IDV), Masculinity (MAS), and the Uncertainty Avoidance Index (UAI) are included in this study. The results show that UAI, PDI and IDV are significant factors relating to this issue.
\end{abstract}

Keywords Hofstede's cultural dimensions · Globalization · Cross-country · Higher education

\section{Introduction}

There is no doubt that globalization is occurring on a significant scale. Globalization, which is defined by Baylis and Smith (1997) as 'the process of increasing interconnectedness between society such that events in one part of the world more and more have effects on peoples and societies far away' (p. 14) is an imperative term that claims that changes have occurred across different aspects of life. The definition above seems to merely describe the general idea of what globalization is bringing to the world, and therefore a clear understanding of how and why globalization has gained such importance is necessary.

H. Y. Cheung $(\bowtie)$

City University of Hong Kong, Kowloon, Hong Kong e-mail: hycheun3@ cityu.edu.hk

A. W. H. Chan

University of Hong Kong, Hong Kong, Hong Kong

e-mail: awhchan@hkusua.hku.hk 
Before the term 'globalization' started to be used in the 1980s, 'international' was the preferred term. The term 'international' refers to forces, processes and institutions based on the system of nation-states, which is also known as state-centrism (Sklair 2001). International organizations are composed of representatives of member countries who act under the instructions of the governments of these countries. However, as the economic, political and cultural ideology started changing around the end of the twentieth century, the world was already revolving beyond the international system of states, mainly due to the rapid advancement of technology. Thus, the term 'globalization' started to appear and has dominated the decisions of people in the business, political and education fields. According to some studies on globalization, nation-states are no longer important parts of the global system (Sklair 2001).

Various terms have been used interchangeably with 'global', for example, international, interterritorial, multinational and worldwide, and globalization has frequently been referred to as internationalization. However, the terms above still cannot fully explain the underlying meaning of globalization. Based on the definition of Weiss (1998), to use the term 'globalization' is 'fundamentally to claim that the nation-state is no longer important either as an actor or as a site of economic accumulation. The existence of a "global" economy ... is synonymous with "transnationalism". It implies an open market place free of institutional or locational constraints...' (pp. 168-169). The term 'transnational' refers to forces, processes and institutions that cross borders but do not derive their power and authority from the state. Again, when applied to the business sector, transnational corporations are owned by shareholders and controlled by Boards of Directors, who can be citizens of any country, and the aim of transnational corporations is to make the corporations as profitable as possible, with no specific privileges extended to their states of origin. Globalization is based on the concept of transnational practices: practices that cross state borders but do not originate with state agencies or actors.

The term 'globalization' conjures up the idea that people nowadays are living in a borderless world where there is an increasing interdependent and sophisticated relationship amongst various aspects of life, such as economies, cultures, institutions and education, and amongst different regions, which thus affects people all over the world. Since distance is no longer an issue, everyone and every region can influence any other people and regions in any aspect, and can also be in competition with any other people or regions. This situation is very different from previous decades in which competition was mainly amongst neighboring regions. Education leaders and policy makers of certain countries realized that they must quickly acclimatize to such changes in order to maintain their competitive edge, hoping that education can increasingly align with the interests of the global market, so that their people can be well prepared and able to function effectively in the competitive global economy.

\section{Enhancing competitiveness through education}

As nations now have to compete both internationally and regionally in order to survive and grow, the need for rapid globalization and economic development has become increasingly intense. In order to enhance competitiveness, governments of different countries have demanded that their people be well prepared for the complex working environment so that they can become stronger economically. Given the pressure of the political economy of globalization, in some countries the education system has been given the responsibility of training people to meet the needs and demands of globalization. Several suggestions have 
been made as to how education can meet the demands of a competitive global economy (Sanchez 2003). For example, since the world emphasizes a knowledge-based environment, it is important for students to be information literate and able to make good use of knowledge. Second, students should be encouraged to be multilingual so that they can play an important role in the global economy in the future. Third, new technology has changed peoples' lives and is also a major source of employment, thus there is a need to train students to be highly skilled in this area. Finally, as the world has become smaller and contact between people around the world has increased, students should be able to work with others both inside and outside the workplace.

Globalization has caused changes in the global economy and in the global political system (Torres 2003), and studies have focused on how these changes have affected education and whether different regions' education systems can meet the competitive demands of the ever-changing economic environment. James and Mok (2003) noted that higher education in Asian countries, such as Hong Kong, Mainland China, Singapore and Taiwan, has adapted to maintain the competitiveness of individual countries. For example, some of the higher education reforms in these Chinese societies are comprehensive reviews of the education system and the policies of decentralization and educational governance. Welch and Mok (2003) analyzed in-depth how some countries in the Asia-Pacific region responded to globalization through the reforms of education. Tobias's article (2002) contributed to the understanding of how professional studies in science and mathematics can help maintain a nation's leadership in a wide range of cutting-edge industries in the United States. Some valuable strategies include contacting local and regional firms to allow students and faculty to be exposed to real-world problems and state-of-the-art instrumentation.

Furthermore, Jordon and Yeoman's study (2003) compared the ways in which England and New Zealand have promoted science and technology education in response to the challenges of rapid technological change and globalization. In England, for instance, there is a policy initiative in science and technology education that involves the establishment of specialist technology colleges charged with promoting provision, participation and achievement in science, mathematics and technology. On the other hand, the New Zealand Science and Technology Teacher Fellowship scheme helps promote science, mathematics and technology as contributing significantly to New Zealand's economy and as rewarding and worthwhile career options. It is becoming more and more popular to link university education to the business sectors in order to have better knowledge production and innovation.

Teacher education has also been affected because of the strong demand for students to learn and think in a 'global manner' in order to prepare for economic globalization, the new knowledge economy and a culture of difference (Hartley 2002). In other words, globalization has caused nearly all aspects, such as business, education, politics, communication and etc., to be networked throughout the world. Although education reform has been affected by the globalized environment, the studies above may imply that education still plays a very significant role, or can be considered as a means through which the demands of globalization, and thus a stronger and a more competitive economy, can be met. Generally speaking, providing a wider range of academic disciplines or curricula can help students gain the skills and knowledge to fulfil the needs of their future employers (Smith 2003; Aberšek 2004; Jang and Kim 2004; Šlaus et al. 2004). A partnership between education and business is, therefore, a good way of giving students an understanding of the ever-changing work environment so that they are more prepared. An important role of education is to train people to be capable of dealing with any crisis by applying 
supranational actions to resolve problems. Overall, education has to be remodeled according to the logic of economy and efficiency.

If a country wants to stay competitive worldwide, it is difficult for its government and citizens not to pay attention to the impact of globalization since it is affecting every aspect of life. Many studies have already focused on how globalization has led to the changes made in different sectors, especially the business sector. However, the impact of how globalization affects the education field needs greater attention since the changes made in the current education sector are going to affect the competitiveness of the future recruits in the society, who are in fact the students studying in primary and secondary schools and universities at present, and eventually affect the overall competitiveness of the country. When compared with primary and secondary education, academic programs offered by universities should be more responsive to globalization because university graduates will directly enter the workforce after the completion of their university programs.

University education nowadays experiences increasing pressure from some governments to demonstrate maximum outputs from the financial inputs they are given. When so many governments, employers and researchers and educators across different disciplines believe that education plays a major part in helping students meet the demands of globalization or global economic competition, which results in stronger nations, it is important to realize that not all nations have responded in the same way due to the specificities of their national histories, politics and cultures (Mok 2003).

As the impact and advantages of being responsive to globalization is so great, as indicated from the above literature review, this study is going to find out why some cultures put an effort in making their education programs to meet the demands of the competitive economy while others do not. This study pays particular attention to the relationship between cultural dimensions and education in efforts to meet the needs of the competitive economy.

\section{Aims of this study}

Many governments, employers and researchers and educators across different disciplines believe that education plays a major part in helping students meet the demands of the competitive economy and thus in producing stronger nations. However, culture affects different nations in different ways in their efforts to meet the needs of the competitive economy through education. Cheung and Chan's study (2007) shows that cultural dimensions play a significant role in influencing the (in)equality of education and career. Moreover, another study by Cheung and Chan (2008) demonstrates that cultural dimensions significantly impact the education expenditure and teacher-student ratio in different educational levels. Therefore, this explorative study seeks to discover if, and how, cultural dimensions influence education in efforts to meet the demands of the competitive economy across regions through a quantitative approach. Forty-three regions with different ratings on the Power Distance Index (PDI), Individualism (IDV), Masculinity (MAS) and the Uncertainty Avoidance Index (UAI) were included in this study and used for analysis. Although some educators may criticize that some studies have relied too much on the framework suggested by Hofstede (Gernon and Wallace 1995), this study hopes to apply Hofstede's cultural dimensions in an attempt to understand the relationships amongst the variables using a quantitative approach. 


\section{Hofstede's cultural dimensions}

Some people think that, as a result of globalization, the world's culture has become increasingly standardized, but in fact, studies have shown that countries tend not to respond to globalization or meet the needs of the competitive economy in the same ways. A nation's culture plays an important role in the process. Culture can be understood as the collective programming of the mind that separates the members from different human groups where each group has its own values (Hofstede and Hofstede 2005). Hofstede and Bond (1988) argue that specific cultural traits of specific nations can be modified but difficult to change, for example, the pragmatic rules of Confucius have dominated Chinese culture since $500 \mathrm{BC}$., and are still the key principles guiding Chinese people's behaviors and thoughts. The Chinese ways of parental control, socialization, the development of children and gender roles, as well as many other aspects of Chinese people are guided by Confucianism (Cheung 1997; Lau and Yeung 1997; Wu 1997). Even for Chinese people who have moved to Western countries, Confucianism still has such a strong guiding influence (Chen et al. 1997). Hofstede (2001) also argues that there exists a cultural dimension, power distance, indicating that there were already centralized governments in the Middle East and democracies in Scandinavia 4,000 years ago. However, as stated by Trompenaars and Hampden-Turner (1998), it is impossible to ever completely understand other peoples' cultures.

Educators tried various ways in analyzing cultures, examples included Bond's Chinese Value Survey (Bond 1988), the Rokeach Value Survey (Thompson 1982) and various others (Robert and Bayacigiller 1984). However, one of the most widely use method is still the cultural dimensions created by Geert Hofstede around the early 1980s (Allan 2002; Dimmock 1998; Paulus et al. 2005; Yates and Cutler 1996). Hofstede's perspective in analyzing cultures is a systematic approach to understanding a society's culture by means of different cultural dimensions, namely the Power Distance (PDI), Individualism (IDV), Masculinity (MAS) and Uncertainty Avoidance (UAI). In later years, Hofstede created another dimension, Long-term Orientation (LTO), however, only 23 regions were included in the data collection for this specific dimension. As a result, data of LTO will not be included in this study for analysis.

PDI is related to human inequality, IDV is about the relationship between the individual and the collective. High MAS societies have men who are tough, and their women are tougher than women in low MAS societies. UAI focuses on the level of tolerance for uncertainty, ambiguity and unstructured situations within a society (Hofstede 1983, 1984; Hofstede and Hofstede 2001).

The dimensions allow people to compare the cultural components of different regions with ease, but they have received some comments by Baskerville's study (2003). Hofstede's cultural dimensions have been commented for holding the assumption of equating nation-states with cultures and quantifying culture based on numeric dimensions. In fact, the cultural dimensions of each region are the basis for the investigation, in which particular nations hold various ratings on each cultural dimension. As mentioned in Baskerville's study (2003), the concept of culture is elusive and embracing, as well as contradictory, thus anything may actually reveal something about one's culture. Some experts from the anthropology and sociology fields may not agree with the application of dimensions or matrices in studying culture. Hofstede's cultural dimensions do contribute to understanding more about culture, but they may not represent everything that the whole culture should have. However, they still provide knowledge about important parts of the overall culture. 
Hofstede's cultural dimensions have also received other remarks, such as concerning problems with his measurement (Robert and Bayacigiller 1984). Various studies have tried to resolve this issue. For example, studies by Hofstede and Bond (1988) and Smith et al. (1996) found that most of Hofstede's cultural dimensions can be associated with cultural factors from Bond's Chinese Value Survey and the well-known Rokeach Value Survey. In addition to this, Hofstede's constructs were validated through establishing the significance of their correlations with geographic, economic and social indicators. With different questions, populations, time periods and mixes of countries, Hofstede's cultural dimensions could still demonstrate similarities with other studies, and these results would not be a mere coincidence.

The current study selected Hofstede's cultural dimensions to investigate the relationships amongst cultural dimensions, education and the competitive economy in a quantitative manner. We believe that the cultural dimensions of IDV, UAI, MAS and PDI can appropriately be related to education that seeks to meet the demands of the competitive economy, since the process of meeting the needs of the competitive economy through education should involve management and decision making by governments, business persons, politicians, educators and the society. Nevertheless, it is important for researchers to be aware of the comments with Hofstede's cultural dimensions. However, the current study's focus is not on the validation of the cultural dimensions. Rather, this study seeks to apply them in an attempt to look at particular relationships from a new perspective.

\section{Data and methodology}

First of all, data from the International Institute for Management Development's (2004) and (2008) World Competitiveness Yearbooks was applied. Since the first publication in 1989 , the yearbook is considered to be one of the most thorough surveys including hundred competitiveness factors from 60 national and regional economies around the world. There were four educational factors that related to meeting the competitive economic environment through education, namely (1) educational system, (2) university education, (3) knowledge transfer and (4) education in finance. A high score in educational system means the educational system meets the needs of a competitive economy. A high score in university education implies that university education meets the needs of a competitive economy. A high score in knowledge transfer suggests that knowledge transfer is highly developed between companies and universities. Finally, a high score in education in finance means that education in finance meets the needs of the enterprises. It is quite obvious that the educational system, including university education, is important in determining the quality of people a country needs to meet the demands of a competitive economic environment. For knowledge transfer and education in finance, when communication is established between companies and universities, it should be easier for universities to provide relevant knowledge to students in order to fulfil the needs of employers who are concerned with being competitive in the market.

In order to analyze the four educational factors from a cultural perspective across regions, this study also includes Hofstede's cultural dimensions (Hofstede 2001). The combination of data from the IMD Competitiveness Yearbook and Hofstede's cultural dimensions were applied in order to achieve the aims of this study. After merging the data sets from the IMD World Competitiveness Yearbook and Hofstede's cultural dimensions, 43 regions were included in this study for analysis (see Table 1 for data from the IMD and Hofstede's cultural dimensions). It is hoped that based on the investigation of these four 


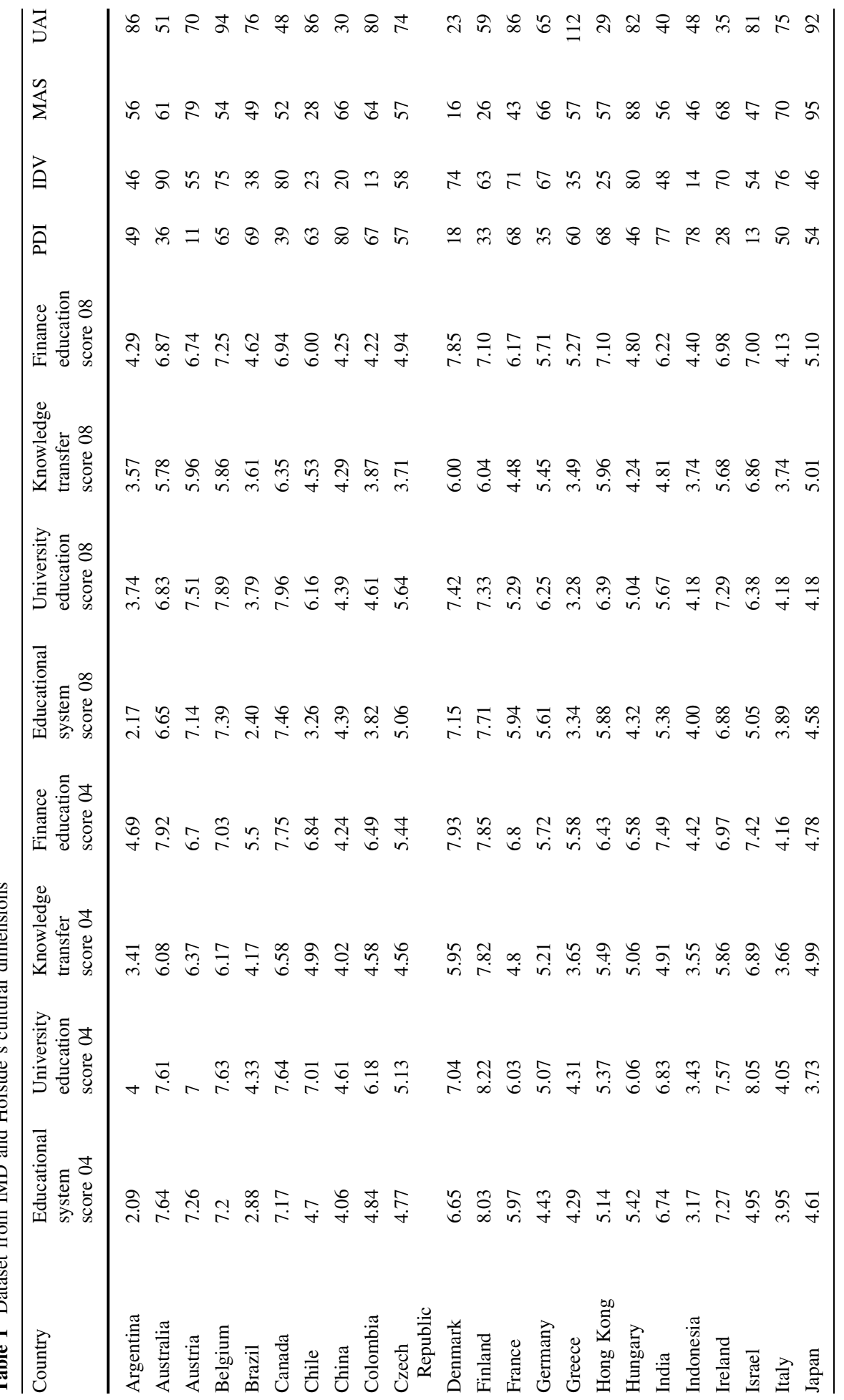




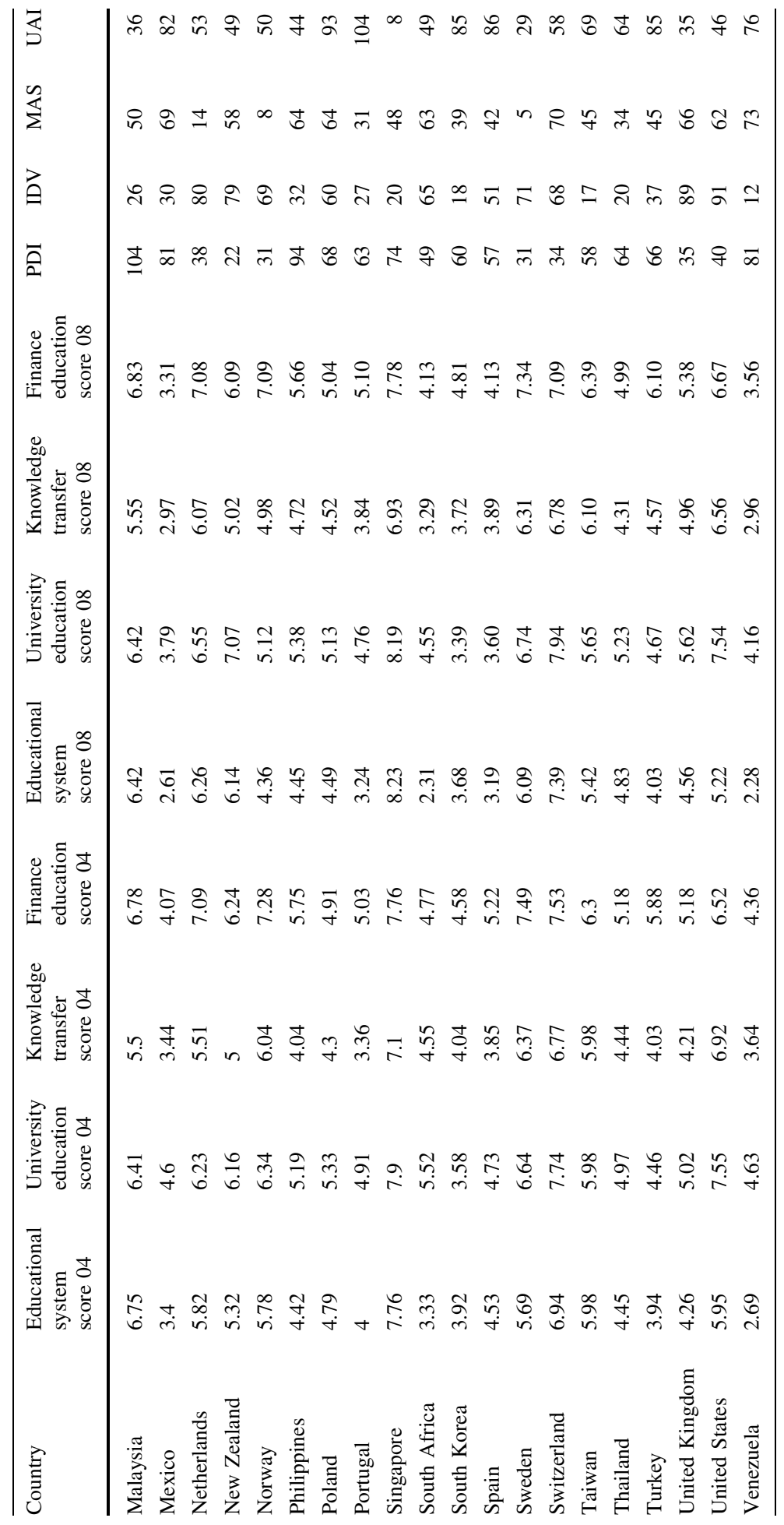


educational factors, using the perspectives of the cultural dimensions, a better understanding of how different regions have used education to meet the needs of the competitive economic environment will be achieved.

As indicated in Table 1, the data for the four educational factors were obtained from the IMD World Competitiveness Yearbook (2004) and the IMD World Competitiveness Yearbook (2008), published by the International Institute for Management Development in Switzerland. The scores of Hofstede's cultural dimensions for our analysis were obtained from Hofstede's book The Culture's Consequences: Comparing Values, Behaviors, Institutions, and Organizations across Nations, published in 2001.

\section{Analyses and results}

Table 2 shows the correlations amongst the variables, PDI, IDV and UAI were significantly correlated with the educational variables. The educational variables between 2004 and 2008 were also highly correlated. Moreover, regression analysis models were run. For the results in Tables 3, 4, 5, and 6, independent variables of IDV, UAI, MAS and PDI were entered into the models. Each table was divided into a and b, for example, Table 5a used cultural dimensions to predict education system of 2004 and Table $5 \mathrm{~b}$ used cultural dimensions to predict education system of 2008.

First of all, the dependent variable, which was the educational system, was entered into Table $3 \mathrm{a}$ and $\mathrm{b}$, and $29 \%$ and $37 \%$ of the variance in the educational system in 2004 and 2008 , respectively were predicted by both UAI and IDV. Then, $31 \%$ and $44 \%$ of the variance in university education in 2004 and 2008, respectively were predicted by PDI and UAI. Forty-two percent and 44\% of the variances in knowledge transfer in 2004 and 2008, respectively were predicted by PDI and UAI. Finally, 37\% and approximately $45 \%$ of the variance in finance education in 2004 and 2008, respectively were predicted by MAS, UAI and IDV/PDI.

\section{Discussion}

This study attempted to apply Hofstede's cultural dimensions to explain why some regions respond differently to the challenge of meeting the needs of the competitive economy through education. The results of this study show that the factors of university education, knowledge transfer and education in finance were significantly explained by PDI and UAI. The factor of the educational system was explained by IDV and UAI. From the results of this study, Hofstede's cultural dimensions could be considered to be important elements affecting the process of education that seeks to meet the needs of a competitive economy. After learning that the cultural dimensions were significant in predicting the variables, it is hoped that other researchers could be stimulated to apply quantitative methods as an additional approach when analyzing their qualitative data on culture. One of Hofstede's aims in his work on cultural dimensions was to stimulate other researchers to come up with more sophisticated cultural models (Tayeb 1996).

As stated by Eckhardt (2002), different researchers have confirmed the cultural dimensions in various cultures around the world. However, national culture, according to some researchers (Harvey 1997), is extremely complex, and these cultural dimensions should not be generalized as constituting an entire nation's culture. In other words, they are not conclusive. The cultural dimensions could be components within larger cultures that 


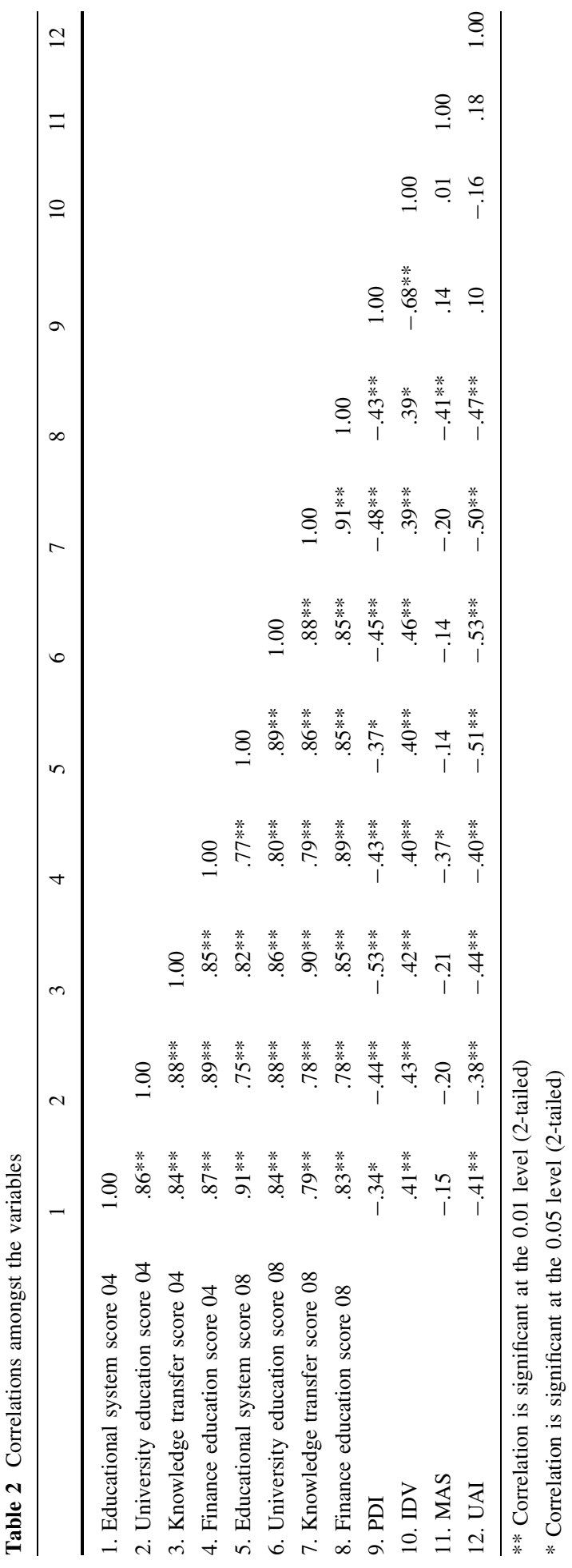


Table 3 Summary of linear regression analysis for Educational System (a) 2004 and (b) 2008 by the cultural dimensions

\begin{tabular}{lrrr}
\hline Variables & \multicolumn{1}{c}{$B$} & SE $B$ & $\beta$ \\
\hline (a) Educational system $2004^{\mathrm{a}}$ & & & $-.35^{* *}$ \\
UAI & -.02 & .01 & $.36^{* *}$ \\
IDV & .02 & .01 & $.33^{* *}$ \\
(b) Educational system 2008 & & & $-.46^{* * *}$ \\
IDV & .02 & .01 & .01 \\
UAI & -.03 & &
\end{tabular}

${ }^{\mathrm{a}} R^{2}=.29 ; \Delta R^{2}=.26(* * * p \leq .001 ; * * p \leq .01 ; * p \leq .05)$

${ }^{\mathrm{b}} R^{2}=.37 ; \Delta R^{2}=.34(* * * p \leq .001 ; * * p \leq .01 ; * p \leq .05)$

Table 4 Summary of linear regression analysis for University Education (a) 2004 and (b) 2008 by the cultural dimensions

\begin{tabular}{llll}
\hline Variables & $B$ & SE $B$ & $\beta$ \\
\hline (a) University education $2004^{\mathrm{a}}$ & & & \\
PDI & -.03 & .01 & $-.41^{* * * *}$ \\
UAI & -.02 & .01 & $-.34^{* *}$ \\
(b) University education 2008 & & & $-.40^{* * * *}$ \\
PDI & -.03 & .01 & $-.49^{* * * *}$ \\
UAI & -.03 & .01 & \\
\hline
\end{tabular}

${ }^{\mathrm{a}} R^{2}=.31 ; \Delta R^{2}=.28(* * * p \leq .001 ; * * p \leq .01 ; * p \leq .05)$

${ }^{\mathrm{b}} R^{2}=.44 ; \Delta R^{2}=.41(* * * p \leq .001 ; * * p \leq .01 ; * p \leq .05)$

Table 5 Summary of linear regression analysis for Knowledge transfer (a) 2004 and (b) 2008 by the cultural dimensions

\begin{tabular}{llll}
\hline Variables & $B$ & SE $B$ & $\beta$ \\
\hline (a) Knowledge transfer 2004 & & & \\
PDI & -.03 & .01 & $-.49^{* * * *}$ \\
UAI & -.02 & .01 & $-.39^{* * * *}$ \\
(b) Knowledge transfer 2004 & & & $-.43^{* * * *}$ \\
PDI & -.02 & .01 & $-.46^{* * *}$ \\
UAI & -.02 & .01 &
\end{tabular}

${ }^{\mathrm{a}} R^{2}=.42 ; \Delta R^{2}=.39(* * * p \leq .001 ; * * p \leq .01 ; * p \leq .05)$

${ }^{\mathrm{b}} R^{2}=.44 ; \Delta R^{2}=.41(* * * p \leq .001 ; * * p \leq .01 ; * p \leq .05)$

might have some effect on the relationships between education and the competitive economy. Similar to the idea of Houston and Eckhardt's study (2001), this study applied Hofstede's cultural dimensions to cross-culturally investigate some macro-level behaviors. Again, as stated above, the aim of this study was not to emphasize national differences; rather, it attempted to investigate how nations with particular ratings of cultural dimensions would respond to the challenge of meeting the needs of the competitive economy through 
Table 6 Summary of linear regression analysis for Finance Education (a) 2004 and (b) 2008 by the cultural dimensions

\begin{tabular}{lccc}
\hline Variables & \multicolumn{1}{c}{$B$} & SE $B$ & $\beta$ \\
\hline (a) Finance education $2004^{\mathrm{a}}$ & & & $.36^{* *}$ \\
IDV & .02 & .01 & $-.32^{*}$ \\
MAS & -.02 & .01 & $-.28^{*}$ \\
UAI & -.01 & .01 & $-.35^{* *}$ \\
(b) Finance education 2004 & & & $-.29^{*}$ \\
PDI & -.02 & .01 & $-.39^{* * *}$ \\
MAS & -.02 & .01 &
\end{tabular}

${ }^{\mathrm{a}} R^{2}=.37 ; \Delta R^{2}=.33(* * * p \leq .001 ; * * p \leq .01 ; * p \leq .05)$

${ }^{\mathrm{b}} R^{2}=.45 ; \Delta R^{2}=.41(* * * p \leq .001 ; * * p \leq .01 ; * p \leq .05)$

education. In the following sections, an analysis of UAI, PDI and IDV will be discussed. The prediction by UAI will be discussed first because it was the most significant cultural dimension amongst the four.

\section{Prediction by UAI}

Amongst the four cultural dimensions, UAI was the strongest predictor of the four educational factors identified by IMD. The relationships between UAI and the four educational factors were significantly negative, which implies that low UAI cultures would score high in educational system, university education, knowledge transfer and education in finance. People in low UAI cultures are less averse to change and are more tolerant of diversity, ambiguity and chaos. They are open to change and innovation, and tend to perceive them as positive opportunities (Hofstede 1984). They are motivated by the 'hope of success'.

From the perspective of the business sector, changes in a low UAI society are rapid and frequent; for example, in the fields of finance and technology. Information and knowledge pour into low UAI societies, and people are receptive to them. In fact, a lack of information of various kinds is the root cause of globalized market failure (Tuijnman 2003). The business sector, therefore, may demand an improvement in its knowledge base of education, training and learning, so that better investment and training choices can be made. Similar to the educational sector, the business sector will encourage different points of view, and communicating with the educational sector is a way of obtaining inspiration. For example, research done by educators and students may lead to innovative solutions to problems. Pevoto (2003) indicated that the global economic environment needs initiative and the ability to adapt to change, respect for diversity and the ability to empower employees, all of which are characteristics of people in high UAI cultures. Overall, with the transfer of knowledge between companies and the educational system, both sides benefit one another in terms of inspiration, new ideas and opportunities.

\section{Prediction by PDI}

Three educational factors identified by IMD could be explained by PDI, and the relationships were significantly negative. This implies that when regions scored low in PDI, 
their scores in university education, knowledge transfer and education in finance would be high. The essence of low PDI cultures is that the gap between powerful and ordinary people is minimized (Hofstede 2001). Everyone in these societies tends to have equal rights, and these cultures encourage interdependence amongst different groups. Communication is reinforced and quality of learning tends to be a two-way communication (Hofstede 1984).

Since low PDI cultures also focus on interdependent relationships amongst different groups, the practical knowledge and experience that students learn in school is beneficial to the business sector when they enter the workforce. Besides this, research carried out by educators and students is also very important in helping the business sector increase its competitiveness within the economy. This is especially important in professional and technical areas, such as finance. As Wyman's study (1997) showed, economic wellness will continue to require education's commitment by using instructional and analytical capacities to meet the needs of the competitive economy. Overall, when two-way communication and interdependence are reinforced in low PDI cultures, the needs of both groups can be better understood. Without the barriers of high and low status or power, employers and people from the educational system are encouraged to consult and learn from each other, and people in such cultures are encouraged to depend on each other in order to achieve optimal results. Meeting the needs of the competitive economy cannot be done without support from people in both the workforce and the educational system.

\section{Prediction by IDV}

Regions with high IDV also scored high in the educational system. People in these cultures are oriented towards competitiveness and believe that ability is one of the most important elements in being successful. It is important for people to have a good career since this is considered a sign of success in high IDV cultures. The purpose of education is to help students learn how to learn and to increase their economic worth (Hofstede 2001). It is not difficult to understand why education is better at meeting the needs of the competitive economic environment in such cultures. In fact, results of Cheung and Chan's study (2007) showed that IDV was able to significantly predict the enrolment of female in primary to tertiary education across 53 countries. Also this cultural dimension significantly affected the income of female and the number of female working in the parliament. The basis of high IDV cultures is that people actually want to be competitive in their jobs and to be financially successful. With this rationale behind them, schools train students to increase their ability and competitiveness so they will be successful in the workforce. A direct way of reaching this goal is to ensure the school curriculum meets the needs of the workforce. Froment (2003) argued that higher education must integrate itself so as to better prepare the highly trained workforce that a region needs if it is to develop the most dynamic and competitive knowledge-based economy in the world.

Take Hong Kong as an example, according to Table 1, the scores for educational system, university education, knowledge transfer and finance education were slightly above average when compared to other regions. The scores for IDV and UAI were quite low and the score of PDI was slight above average. According to results of this study, lower UAI score could predict higher scores on the four variables of IMD. Obviously, UAI seemed to have it function in Hong Kong.

According to the information from Bray and Koo (2004), Hong Kong is located on the south coast of China, has been colony of the British power until July 1, 1997, and is now 
one of the Special Administrative Regions of the People's Republic of China. The majority of people living in Hong Kong are Cantonese-speaking Chinese and the official language is Chinese. Hong Kong is an international city locating in the heart of Asia. Some of Hong Kong important industries include finance and banking, accounting and legal, tourism, telecommunications and media, importing and exporting. Hong Kong attracts people from all over the world to do business and tour around the city. Thus, Hong Kong people are used to changes and are able to tolerant diversities and ambiguities. Hong Kong people, especially the ones in the business and industry sectors, are very open to innovation and will see them as opportunities and motivation. In order to be successful in the Hong Kong society, people must be receptive to new information and knowledge since a lack of information may be the cause of globalized market failure.

According to the study by Mok and Wilding (2003), the Hong Kong government has perceived providing quality education as the key to the future development of Hong Kong in the twenty first century. In 1999, the Chief Executive already pointed out that "the quality of our people has a direct bearing on Hong Kong's competitiveness in the next century...To realize our vision of Hong Kong as a world-class city with a thriving economy and an affluent and culturally rich society, it is first and foremost necessary to cultivate and retain a critical mass of talented people" (Mok and Wilding, pp. 138-139). It is believed that providing quality education is a significant role of education so as to teach basic knowledge and skills to students and to train them to become independent and lifelong learners in order to handle problems in this fast-changing society.

The Hong Kong government has tried to restructure the education system to achieve its goals. For example, in the primary and secondary school levels, the School Management Initiative scheme has provided the schools more decision-making power and autonomy in using resources. The purpose behind this scheme is to transform schools into dynamic and accountable professional learning communities so that a world-class school system can be achieved in Hong Kong. In terms of higher education, many different strategies have been applied, for example the establishment of quality assurance exercises (including the research assessment exercise (RAE), teaching and learning quality review and management review) and the implications of a management-oriented approach to quality education (Mok and Wilding 2003). The RAE has been a very significant exercise amongst Hong Kong universities. By meeting the standards of RAE, scholars are able to update knowledge in their specific fields through publishing their research in international journals. Besides making sure that university lecturers keep close to what are happening in their areas, students will be guaranteed to learn the most updated information from their lecturers. Overall, the Hong Kong government is aiming to further create the education services to be more efficient and effective. According to the above education reforms, the Hong Kong government hopes to increase the educational quantification and measurement of outputs and outcomes and also to adopt the market-oriented strategies in order to increase the competitiveness of people in Hong Kong. Generally speaking, all of the above educational strategies aimed to meet the needs of the competitive economy.

Unfortunately, PDI and IDV did not seem to show significant results in the situation of Hong Kong. Anyhow, the results in Tables 2, 3, 4, and 5, show that the cultural dimensions were only able to predict approximately $35 \%$ of the variance in the variables identified by IMD. Other unknown but significant variables may be able to predict the remaining $65 \%$. Thus, the reciprocal advancement of the region's economical, historical and political systems is equally essential. 


\section{Conclusion}

One of the limitations of this study is that it only included 43 regions. Also, this study applied only four educational factors, namely educational system, university education, knowledge transfer and education in finance, for analysis. Other important educational variables, such as education in different academic areas, were unknown due to unavailability of data.

Generally speaking, it is believed that globalization has created a global culture, and if this global culture is shared by all nations, the jobs of business managers and policymakers will be easy to perform (Trompenaars 1994). Even in this highly globalized competitive environment, every region has its own culture that affects people's thoughts and behaviors. Results of this study made a contribution in understanding why some cultures do not respond as closely to the demand of globalization through education as other cultures do. Overall, this study has found that cultural dimensions were able to influence how regions meet the needs of the global competitive economy by means of educational variables, namely education system, university education, knowledge transfer and education in finance. It is hoped that this study has provided a new perspective for looking into macro-level issues by investigating the cultural dimensions found in different regions.

\section{References}

Aberšek, B. (2004). Vocational education system in Slovenia between the past and the future. International Journal of Educational Development, 24(5), 547-558.

Allan, M. (2002). Cultural borderlands: Cultural dissonance in the international school. International Schools Journal, 21(2), 42-53.

Baskerville, R. F. (2003). Hofstede never studied culture. Accounting, Organization and Society, 28, 1-14.

Baylis, J., \& Smith, S. (1997). The globalization of world politics: An introduction to international relations. Oxford: Oxford University Press.

Bond, M. H. (1988). Finding universal dimensions of individual variation in multicultural studies of values: The Rokeach and Chinese Value Surveys. Journal of Personality and Social Psychology, 55(6), 10091015.

Bray, M. B., \& Koo, R. (2004). Education and society in Hong Kong and Macao: Comparative perspectives on continuity and change. Hong Kong: Comparative Education Research Center.

Chen, C. S., Lee, S. Y., \& Stevenson, H. W. (1997). Academic achievement and motivation of Chinese students: A cross-national perspective. In S. Lau (Ed.), Growing up the Chinese way (pp. 69-92). Hong Kong: The Chinese University Press.

Cheung, F. M. (1997). Gender role development. In S. Lau (Ed.), Growing up the Chinese way (pp. 45-67). Hong Kong: The Chinese University Press.

Cheung, H. Y., \& Chan, A. W. H. (2007). How culture affects female inequality across countries: An empirical study. Journal of Studies in International Education, 11(2), 157-179.

Cheung, H. Y., \& Chan, A. W. H. (2008). Relationships amongst cultural dimensions, educational expenditure and class size of different nations. International Journal of Educational Development, 28, 698-707.

Dimmock, C. (1998). Restructuring Hong Kong's schools: The applicability of western theories, policies and practices to an Asian culture. Educational Management and Adminstration, 26(4), 363-377.

Echkhardt, G. M. (2002). Review of the book Culture's consequences: Comparing values, behaviours, institutions and organizations across nations. Journal of Marketing, 27(1), 89-94.

Froment, E. (2003). The European higher education area: A new framework for the development of higher education. Higher Education in Europe, 27(1), 27-31.

Gernon, H., \& Wallace, R. S. O. (1995). International accounting research: A review of its ecology, contending theories and methodologies. International Accounting Research, 14, 54-106. 
Hartley, D. (2002). Global influences on teacher education in Scotland. Journal of Education for Teaching, 28(3), 251-255.

Harvey, F. (1997). National cultural differences in theory and practice: Evaluating Hofstede's national cultural framework. Information Technology \& People, 10(2), 132-146.

Hofstede, G. (1983). Culture and management development. Geneva: Management Development Branch, Training Department.

Hofstede, G. (1984). Culture's consequences (Vol. 5). London: Sage Publications.

Hofstede, G. (2001). Culture's consequences: Comparing values, behaviors, institutions, and organizations across nations (2nd ed.). Beverly Hills: Sage Publication.

Hofstede, G., \& Bond, M. H. (1988). The Confucius connection: From cultural foots to economic growth. Organizational Dynamics, 16(1), 5-21.

Hofstede, G., \& Hofstede, G. J. (2005). Cultures and organizations: Software of the mind. New York: McGill-Hill.

Houston, M. J., \& Echardt, G. M. (2001). Culture's consequences on consumer behaviour towards food in Asia. Asian Journal of Marketing, 8(2), 33-54.

International Institute for Management Development. (2004). The World competitiveness yearbook 2004. Switzerland.

International Institute for Management Development. (2008). The World competitiveness yearbook 2008. Switzerland.

James, R., \& Mok, K. H. (2003). Editorial. Higher Education Research and Development, 22(2), 115-116.

Jang, S. Y., \& Kim, N. H. (2004). Transition from high school to higher education and work in Korea, from the competency-based education perspective. International Journal of Educational Development, 24(6), 691-703.

Jordan, S., \& Yeomans, D. (2003). Meeting the global challenge? Comparing recent initiatives in school science and technology. Comparative Education, 39(1), 65-81.

Lau, S., \& Yeung, P. P. W. (1997). Understanding Chinese development: The role of culture in socialization. In S. Lau (Ed.), Growing up the Chinese way (pp. 29-44). Hong Kong: The Chinese University Press.

Mok, K. H. (2003). Globalization and higher education restructuring in Hong Kong, Taiwan and Mainland China. Higher Education Research and Development, 22(2), 117-129.

Mok, K. H., \& Wilding, P. (2003). The quest for quality education and learning society in Hong Kong. In K. H. Mok \& A. Welch (Eds.), Globalization and educational restructuring in the Asia pacific region (pp. 128-332). New York: Palgrave.

Paulus, T. M., Bichelmeyer, B., Malopinsky, L., Pereira, M., \& Rastogi, P. (2005). Power distance and group dynamics of an international project team: A case study. Teaching in Higher Education, 10(1), 43-55.

Pevoto, B. (2003). Leadership opportunities for women in career and technology education. Workforce Education Forum, 30(1), 52-70.

Robert, K. H., \& Bayacigiller, N. A. (1984). Cross-national organizational research: The grasp of the blinded men. Research in Organization Behavior, 6, 425-476.

Sanchez, F. (2003). Skills for a knowledge-based economy. Leadership, 33(2), 30-33.

Sklair, L. (2001). Transnational capital class. UK: Blackwell Publisher Ltd.

Šlaus, I., Šlaus-Kokotović, A., \& Morović, J. (2004). Education in countries in transition facing globalization-a case study Croatia. International Journal of Educational Development, 24(5), 479-494.

Smith, D. (2003). Partnerships: Curriculum that mirrors the real world. The Presidency, 1, 31-33.

Smith, P. B., Dugan, S., \& Trompenaars, F. (1996). National culture and the values of organizational employees: A dimensions analysis across 43 nations. Journal of Cross Cultural Psychology, 27(2), 231-264.

Tayeb, M. H. (1996). Hofstede. In M. Warner (Ed.), International encyclopedia of business and management (Vol. 2, pp. 1771-1776). London: Thompson.

Thompson, B. (1982). Validity of Rokeach Value Survey. Educational and Psychological Measurement, 4(3), 899-905.

Tobias, S. (2002). The newest master's professional studies in the sciences and mathematics. Change, 34(6), 29-34.

Torres, C. A. (2003). Comparative education: The dialectics of globalization and its discontents. In R. F. Arnove \& C. A. Torres (Eds.), Comparative education: The dialectic of the global and the local (pp. 1-23). UK: Rowman \& Littlefield Publishers, Inc.

Trompenaars, F. (1994). Riding the waves of culture: Understanding diversity in global business. NY: Irwin.

Trompenaars, F., \& Hampden-Turner, C. (1998). Riding the waves of culture: Understanding cultural diversity in global business (2nd ed.). NW: McGraw-Hill.

Tuijnman, A. (2003). Measuring lifelong learning for the new economy. Compare, 33(4), 471-482. 
Weiss, L. (1998). The myth of the powerless state. UK: Polity Press.

Welch, A. R., \& Mok, K. H. (2003). Conclusion: Deep development or deep division. In K. H. Mok \& A. R. Welch (Eds.), Globalization and educational re-structuring in the Asia Pacific Region (pp. 333-355). London: Palgrave.

Wu, D. Y. H. (1997). Parental control: Psychocultural interpretations of Chinese patterns of socialization. In S. Lau (Ed.), Growing up the Chinese way (pp. 1-28). Hong Kong: The Chinese University Press.

Wyman, S. M. (1997). A new vision for continuing higher education: Creating economic wellness. New Directions for Higher Education, 25(1), 5-16.

Yates, G. C., \& Cutler, B. D. (1996). Hofstede's model of national culture: A social science contribution to international business. Journal of Teaching in International Business, 8(2), 77-93. 